\title{
Design and Implementation of Resource Management System for the Philosophy of Science
}

\author{
Zhe $\mathrm{Li}^{1, \mathrm{a}}$, Deyin $\mathrm{YaO}^{2, \mathrm{~b}}$ \\ ${ }^{1}$ College of International Exchange, Bohai University, Jinzhou, 121013, China \\ ${ }^{2}$ College of Engineering, Bohai University, Jinzhou, 121013, China \\ a503412508@qq.com, bdeyinyao2013@gmail.com
}

Keywords: philosophy of science; teaching resources; resources library; management system

\begin{abstract}
Philosophy of science is a comprehensive discipline. With the development and popularization of the network, more and more aspects of life are inseparable from the network, especially in teaching education. In order to fit the development of modern educational technology, the establishment of network teaching resources library for the philosophy of science also more and more receives takes. This paper conducted a more systematic planning and design for resources library management platform of the philosophy of science combined with the actual situation. Firstly, the paper elaborated that the system is divided into four functional modules, and then the functions of each module was introduced; then, design process of the system was described; finally, the paper carried on database design. The development of resources library management system for the philosophy of science has great significance in improving the efficiency of resources management overall and realizing the sharing of teaching resources.
\end{abstract}

\section{Introduction}

The philosophy of science is the important branch of philosophy, it main studies the general rule of nature, the basic method of science and technology activities, science and technology and the philosophy issues in the development process and so on. Similarly, philosophy of science and technology is the branch of philosophy, but it is a highly comprehensive, strong qualitative methodology discipline spanned between the humanities and social science and natural science rather than a simple humanities and social science or natural science. With the popularity of the internet and improvement of the campus network construction, using network in education and teaching is more and more common [1]. Network teaching resource library for the philosophy of science is established in order to adapt to the development of modern educational technology and promote networking of education, informationization process. Network teaching resource library bases on "server/client" structure in line with the technical specifications of the campus network. Resource library management system (software platform) is the basic platform to support resource management and use [2]. In the final analysis, this system is to facilitate management of philosophy of the science resources in the teaching process and reduce the workload related to blind search, so the system can improve work efficiency as much as possible to save waste of human and material [3]. Teaching resources of schools can maximize the use of each other, which can achieve the standardization and scientification of resource management.

\section{System Functional Model Design}

Software development should follow strict norms, and modular design of system should be conducted. Modular simply put, the system can be divided into a number of modules and each module completes a specific function, and then these modules will be assembled to form a whole (systems), which can complete specified function [4]. Modular has advantages of high reliability, easy to modify and so on. In order to make teaching resource library to complete the operation and use, the system can be divided into four parts according to different roles, respectively are administrator module, teacher module, student module and tourist module [5]. 
After full system analysis, the main modules of the system include the following aspects:

(1) Administrator module. System administrators can manage users and give permission for newly registered users, regardless of the users' information or authority. System administrators also can manage resource library of philosophy of science, including resource upload, download, search and browse. Beyond that, administrators must review upload resources to ensure security and legitimacy of resources.

(2) Teacher module. The teachers can view and modify their own information and carry out a series of operations on resources after landing system. Teachers can upload resources to communicate with other teachers and students.

(3) Student module. After landing system, students can also view and modify their own information. In addition, students are able to search, browse, upload and download resources.

(4) Tourist module. Tourists enter into the system as the status of purely unregistered visitors, and their permissions are very limited as opposed to registered users. They only can carry out single operation for the resources, such as just simple search, browse and download resources.

System functional model diagram shows in Fig. 1.

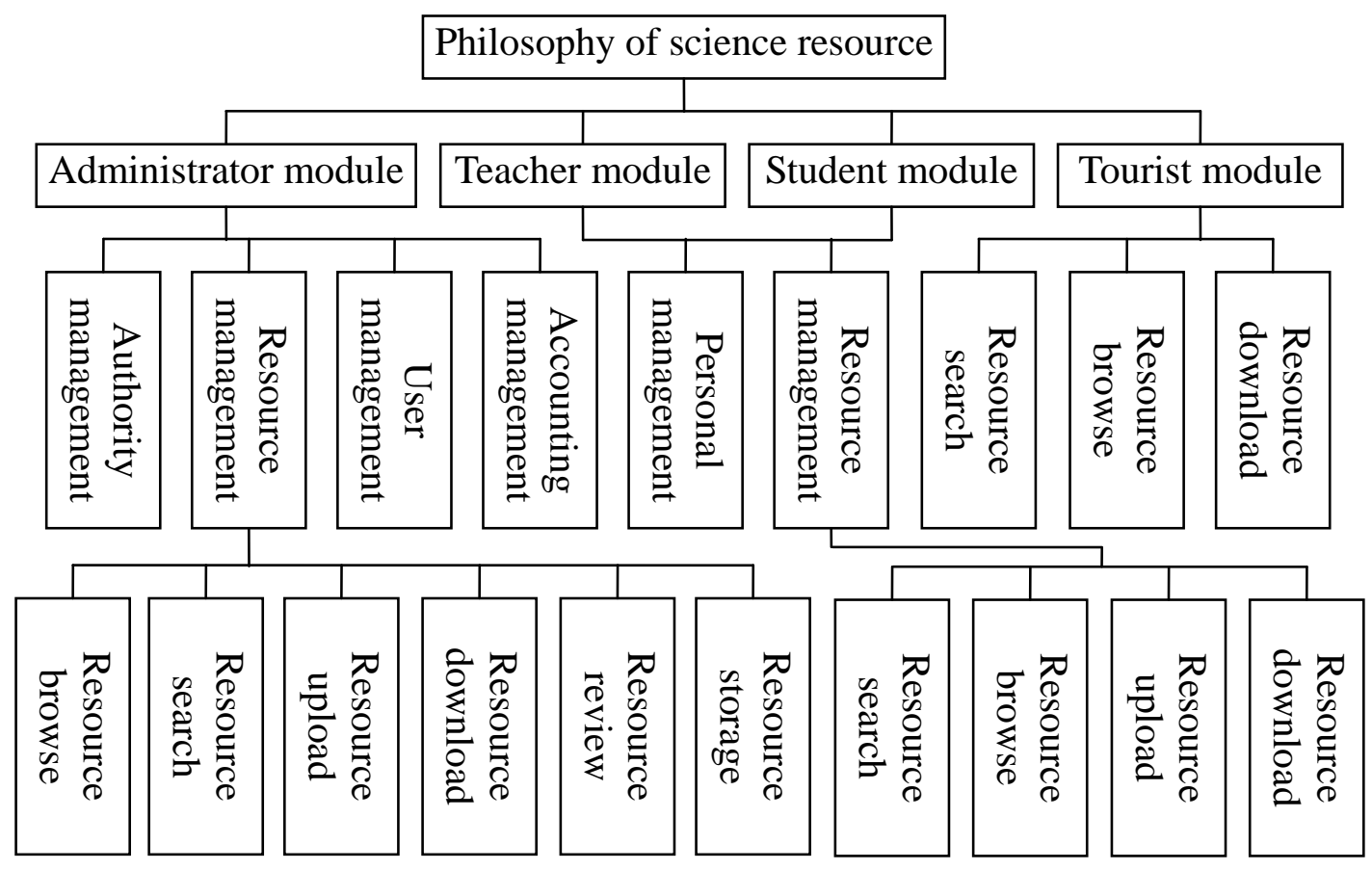

Fig.1. System functional model diagram

\section{System Program Process Design}

Users in the system are divided into two categories, the one is the system administrator who can control and manage resource library management system of philosophy of science. They can manage the upload and download of resources or manage users, such as deleting and adding new users and so on, and they give the permission to users; another type of user is the teacher, student and tourist. Such users use resource library management system of philosophy of science [6], such as searching, browsing and downloading resources. Because this system has two types of users, now taking the system administrator for example, specific process diagram of using and managing system shows in Fig. 2.

Users enter into system landing page by the home page, then the administrator inputs user name and password, if verification is not passed, it will prompt that the user name or password is incorrect and continue to remain in the landing page; if verification is passed and determine that the user is administrator, then you will enter personal information page. Then the users' permission will 
be given, and the user can carry out the operation of relevant authority.

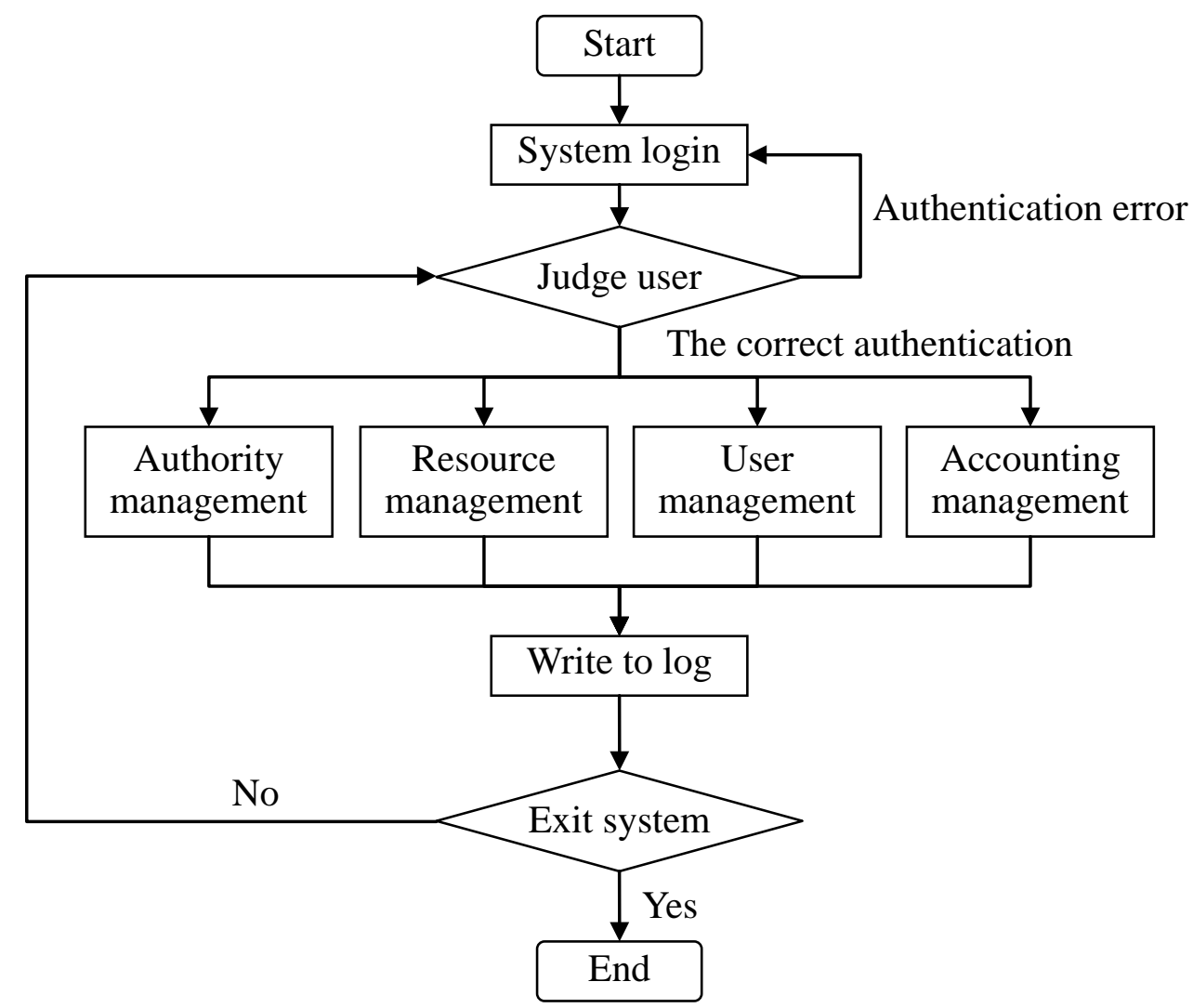

Fig.2. System process diagram

\section{Database Design}

Database is a permanent, self-describing data warehouse stored in one or more files. The database design is used to structure the optimal database schema, and establish database and applications for a given application environment, so they enable to store data efficiently and meet application requirements of various users (information requirements and processing requirements). Database design is an important part of the development and construction of information system. So before you started working on the construction of this resource library management system, the data in this system must be carried on detailed classifying and specific structure designing. Database design must achieve clarity and adapting to the call of system function so as to avoid the logical confusion error on structure and so on [7]. The database is the key to ensure that information system can be tightly bound together with the respective parts. Its design is critical in the development of a system, and it will directly affect the performance of the whole system [8].

The system uses the relational model in order to improve the efficiency of query. Database is established on the server, it includes:

User information table: the users in system include system administrators, teachers and students. The table records the users' basic information, including number, name, password, command, group code, department, position, date of birth, education, communication and other information;

Resource information table: It is mains used to record basic information of uploaded resources, such as resource type, upload user, user code, upload time, download times, storage path;

User group table: It is used to record user group code and group name, including two fields: the first is group code; the second is group name, and it has the relationship of one to many with the user information table;

Permission table: It records codes and names of all functions of application. Among them, the value of authority code cannot be 0 . When you read, the value of 0 is deleted, which is not authorized if it value is 0 . 
Group permission table: It records permission of each group. A user group has several kinds of permissions, and a permission belongs to many user groups. User groups have the relationship of many to many with permissions. A link table (group permissions table) is added based on the principles of database design, and the relationship of many to many will be converted into two relationship of one to many.

\section{Conclusion}

With the study of philosophy of science is getting seriously, so the teaching resources of the philosophy of science constantly are enriched and e-learning system based on campus network is also more perfect. Therefore, the management for philosophy of science resources is proposed to have higher-level requirements. Excellent courseware produced by teachers and a variety of resources only exists in teachers' hands of their own, but cannot share and exchange with others, so resulting in low utilization of resources and even waste. Aiming at the problems and challenges of the management of resource library, and combining with the actual situation of teaching, teaching resources will be unified integrated and managed to propose a resource library management system for the philosophy of science based on "client/server" structure. Resource library includes various types of resources [9]. The resource library management system is divided into four functional modules according to different users. In this paper, resource library management system is introduced from three aspects, namely are system functional model design, process design and database design. The design for resource library management system for philosophy of science has a relatively strong operability, practicability and reference for the future development of school education.

\section{References}

[1] H. Y. Wang, "Design and Implementation of Network Based on Teaching Resource Management System," Journal of Anshan Normal University, vol. 11, no. 6, pp. 53-56, 2009.

[2] J. C. Deng, "Design and Implementation of a Centralized Teaching Resource Management System Based on Network Environment," Financial Computer of Huanan, vol. 16, no. 7, pp. 47-49, 2007.

[3] J. R. Wang, N. N. Gao, K. W. An, "Design and Implementation of Teaching Resources Management System in Xinjiang High School," Journal of Xinjiang Vocational University, vol. 17, no. 3, pp. 77-79, 2009.

[4] Baidu Encyclopedia, "Modularity," http://baike.baidu.com/view/182267.htm, 2014-9-3.

[5] J. M. Guo, "The Teaching Repository's Design Based on The Chinese Subject Essence in Junior Middle School," Master's degree of Northeast Normal University, 2013.

[6] Y. M. Liu, "Design and Implementation of Teaching Resources Management Based on J2EE Framework," Master's degree of University of Electronic Science and Technology of China, 2013.

[7] H. T. Tu, "University Educational Subsystem-Design and Implementation of Teaching Resource Management System," Master's degree of University of Electronic Science and Technology of China, 2011.

[8] H. B. Li, L. Liu, "Design and Implement of Management System of Elementary Education Resources Database Based on MVC Pattern," Modern Educational Technology, vol. 16, no. 1, pp. 43-46, 2006.

[9] R. L. Zhang, "Design and Implementation of Educational Resources Database Management System," Master's degree of University of Electronic Science and Technology of China, 2010. 